\title{
Do Increasing Contents of Methane and Carbon Dioxide in the Atmosphere Cause Global Warming?
}

\author{
G. V. Chilingar, O. G. Sorokhtin, L. F. Khilyuk, M. Liu* \\ Russian Academy of Natural Sciences, US Section, Los Angeles, USA \\ Email: ${ }^{*}$ Imfusc2012@gmail.com
}

Received 26 September 2014; revised 27 October 2014; accepted 10 November 2014

Academic Editor: Mohammad Valipour, University of Tehran, Iran

Copyright (C) 2014 by authors and Scientific Research Publishing Inc.

This work is licensed under the Creative Commons Attribution International License (CC BY).

http://creativecommons.org/licenses/by/4.0/

(c) (i) Open Access

\section{Abstract}

In the Earth atmosphere, methane gradually converts into carbon dioxide which, according to the conventional anthropogenic theory of global warming, is the main driver of global climate change. The authors investigated the greenhouse effect of methane and carbon dioxide in the atmosphere using their tested adiabatic model, which relates the global temperature of troposphere to the atmospheric pressure and solar activity. This model allows one to analyze the global temperature changes due to variations in mass and chemical composition of the atmosphere. Even significant releases of anthropogenic carbon dioxide and methane into the atmosphere do not change average parameters of the Earth's heat regime and have no essential effect on the Earth's climate. Thus, petroleum production and other anthropogenic activities resulting in accumulation of additional amounts of methane and carbon dioxide in the atmosphere have practically no effect on the Earth's climate.

\section{Keywords}

Global Warming, Carbonate Dioxide, Methane

\section{Introduction}

The content of methane in the atmosphere had been gradually increasing over the last century. In spite of the fact that the methane content constitutes only about $1.8 \mathrm{ppm}$ in the Earth's atmosphere, the national and interna-

${ }^{*}$ Corresponding author. 
tional policy makers declared the methane gas extremely dangerous to the Earth climate because of a high potency (about 100 times more potent than $\mathrm{CO}_{2}$ over the time span of 20 years) of its molecules to absorb the infrared radiation. Together with the growing contents of $\mathrm{CO}_{2}$ and other greenhouse gases it supposedly causes drastic changes in the Earth's climate. According to the conventional anthropogenic theory of global warming as a result of absorption of the infrared radiation by the molecules of the greenhouse gases, these molecules intercept infrared photons in the lower layer of troposphere warming the Earth climate. This anthropogenic theory is the "scientific" basis for strong political and economic actions against further expansion of fracking, for example, in the shale-gas production.

The conventional anthropogenic theory (backed and promoted by IPCC and other national and international organizations over the last 25 years) completely ignores the main physical phenomena of the heat transfer in the atmosphere. In particular, it assumes that the heat transfer in atmosphere occurs exclusively by radiation. Meantime in the lower dense layer of troposphere it occurs mostly by convection ( $67 \%$ by convection, $8 \%$ by radiation, and $25 \%$ by water vapor condensation) [1], which is intensified considerably with any additional release of the so-called greenhouse gases. Moreover, analyzing the postulates of the conventional theory one can find out that this theory completely ignores the fact that molecules of methane and other greenhouse gases $\left(\mathrm{H}_{2} \mathrm{O}\right.$, for example) intercept the infrared solar irradiation in the upper layers of stratosphere and, thus, prevent overheating of Earth.

A renowned Swedish scientist, Svante Arrhenius (1896) [2] was the first to forward the idea of Earth's atmosphere heating by the greenhouse gases. Since then, the concept was taken for granted as obvious without any verification (Budyko, 1997 [3]; Global warming, 1993; Greenhouse effect, 1989).

Unfortunately, this view totally dominates conclusions by experts from the Intergovernmental Panel on Climate Change (IPCC) on the climate change, by Greenpeace, UN Environmental Program, World Meteorological Organization (WMO), as well as the conclusions of the European and Russian Environmental organizations.

According to the forecasts based on these ideas, by 2100 climate warming may reach $2.5^{\circ} \mathrm{C}$ to $5^{\circ} \mathrm{C}$ and the associated rise in the ocean level, of 0.6 to $1 \mathrm{~m}$, which may create problems for densely populated areas of the continental coastal regions as well as for the gas- and oil-industry in some areas of the world. Other deleterious consequences of the global warming are also forecasted (expansion of the deserts, melting of the permafrost, soil erosion, etc.).

The concern about similar catastrophic phenomena and the pressure tactics from the environmental groups, and often mere political and religious speculations on the subject [4] are forcing the governments of developed countries to allocate huge funds for a fight with the consequences of the climate warming ostensibly caused by the man-made releases of "greenhouse" gases into the atmosphere. How justified are these expenses?

A close review of the problem showed that prior to 1990s there was no physical theory of the greenhouse effect fitted to the data of observations. The first publication on the subject was in 1990 [5]. Before of this, all estimates of the $\mathrm{CO}_{2}$ and other greenhouse gases effect on Earth's climate were and, unfortunately, are still performed using different subjective computer models and numerous, but not always stable, parameters.

There are direct evidences of the fact that the changes in the partial $\mathrm{CO}_{2}$ pressure in the atmosphere are the effect and not the cause of the climate change [6]. When drilling through the ice sheet at the Antarctic Vostok Station [7], oceanic average temperature (water evaporation from the oceans formed this very ice sheet) as well as $\mathrm{CO}_{2}$ contents in the air bubbles from the ice were determined. The oceanic water evaporation temperature was determined from isotopic shifts for oxygen and hydrogen (deuterium). Strong direct correlation was observed between these parameters over the entire studied Antarctic ice accumulation history of $420 \mathrm{MY}$ (see Figure 1). It was found, based on temporal analyses, that temperature changes occurred first, and then were followed in 500 to 600 years by the changes in $\mathrm{CO}_{2}$ concentration [8].

This result is practically a monosemantic statement of the fact that the fluctuations of $\mathrm{CO}_{2}$ concentration in the atmosphere are the effect and not the cause of the climate changes. Besides, the time interval of 500 to 600 years well correlates with the time of complete stirring of the upper, active layer of the World Ocean.

The $20^{\text {th }}$ century warming has the clear natural origin and may soon be replaced by a new cooling-down phase [9]. The instrumental temperature observations were conducted in Southern England since 1749. Solar magnetic activity was recorded in France as the number of Sun spots (the Wolfe numbers) since the 1750's. The comparison of these data shows extremely high correlation between the near-surface Earth's temperature and solar magnetic activity. Thus, the forecasts of the Earth's climate changes cannot be made without the consideration of the periodic changes in solar activity. 


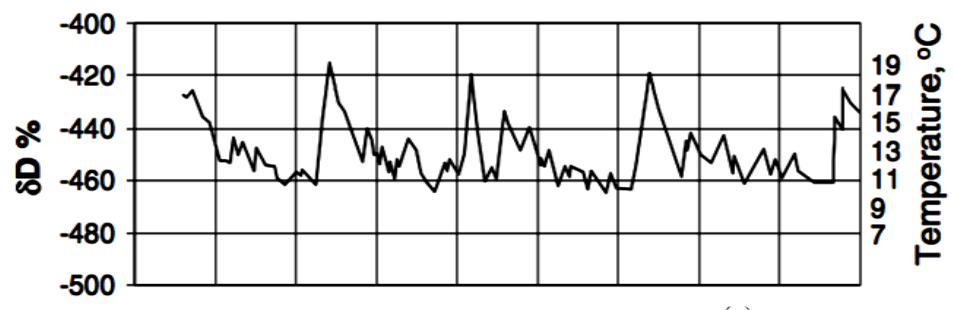

(a)

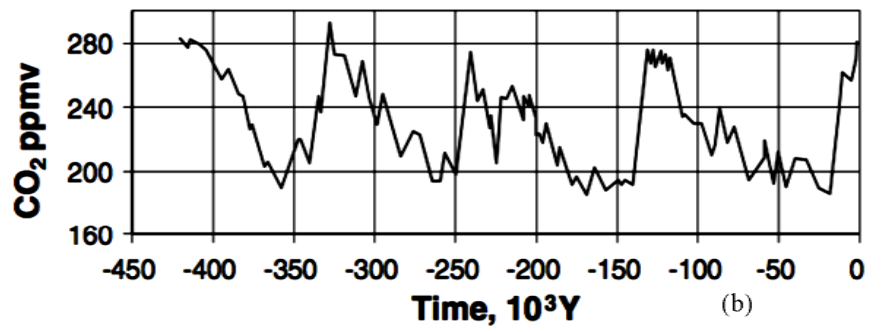

Figure 1. Isotopic air temperature (a) vs. carbon dioxide concentration (b) over the recent $420 \mathrm{MY}$ on the "Vostok" Antarctic station. Field data of the $\mathrm{CO}_{2}$ concentrations and temperature derived from the cores of a well drilled to $\mathrm{TD}=3623 \mathrm{~m}$ were kindly provided by V. M. Kotlyakov (2000) [7] (the scale of Earth's average temperatures is our interpretation).

The writers developed a physical model of heat transfer in the atmosphere that includes the most significant parameters of the medium and the definitive characteristics of the climate drivers. This model includes the averaged value of the Sun radiation energy impinging the Earth, average atmospheric pressure and atmospheric heat capacity as well as the effect of the negative feedback between the tropospheric albedo and of the average surface temperature. Thus, one can obtain the most reliable parameters of the greenhouse effect although Earth with this approach is just a dimensionless point. This model, in particular, allows analyzing the effect of additional contents of the "greenhouse" gases on the average Earth's temperature providing numerical estimates of the temperature changes due to any variations in the atmospheric composition. This tested model [1] [10] may be considered one-dimensional as it describes the correlation of the tropospheric temperature with elevation over the planet's surface.

This approach has definite advantages for the purposes of decision making as it allows for the derivation of the analytical singular result in the solution of global problem, for instance such as the effect of the atmosphere on the total value of its greenhouse effect (for Earth as a whole). The single-dimensional model is amenable to the inclusion of additional and local parameters. These parameters may be, for instance, Earth revolution axis angle with the ecliptics, inflow of the additional heat through the air mass (cyclones) currents, and snow cover albedo [1].

\section{Fundamentals of the Adiabatic Theory of the Heat Transfer in the Earth's Atmosphere}

It is most convenient to select Earth's average surface temperature $T_{s}$ as a main variable characterizing the averaged global climate (the current value is $T_{s}=288.2 \mathrm{~K} \approx 15^{\circ} \mathrm{C}$ ). As opposed to the classical approach, we will assume that the main mechanism of heat release from the surface of the planets with a dense atmosphere (the atmospheric pressure $p>0.2 \mathrm{~atm}$ ) is the convective air mass transfer in the troposphere. In this case, the temperature distribution in the troposphere on average must be close to adiabatic, and average planet's surface temperature will depend on the solar constant $S$, the atmospheric pressure $p$, the precession angle $\psi$ of the revolving planet, its albedo $A$ and the effective value of the albedo exponent $\alpha$ (determined by the troposphere gaseous composition and humidity).

It is known that the adiabatic temperature distribution is controlled by the atmospheric pressure $p$ and the effective gas heat-capacity [11]: $T^{\gamma} \cdot p^{1-\gamma}=$ const and $\gamma=c_{P} / c_{V}$, where $c_{p}$ and $c_{v}$ are the gas heat-capacities under constant pressure and constant volume, respectively. Then the $T(p)$ may be found as: 


$$
\begin{gathered}
T=C \cdot p^{\alpha} \\
\text { where } \alpha=\frac{\gamma-1}{\gamma} \text { and } \gamma=\frac{c_{P}}{C_{V}} .
\end{gathered}
$$

It shows that under adiabatic process the gas temperature in degrees Kelvin $(\mathrm{K})$ is always proportionate to the gas pressure $p$ to the power of the adiabatic exponent $\alpha$ which is a function of the effective heat capacity of the atmospheric gas mixture. The negative feedback pertaining to the solar radiation transformation by the cloud cover must be taken into account: the cloud cover usually plays a major role in the formation of the planet's albedo.

In the previous publications [1] [6] the authors derived the main equations and showed that temperature distribution in dense $(p>0.2 \mathrm{~atm})$ troposphere is ruled by the following law:

$$
T_{t}=b^{\alpha} \cdot\left[\frac{S(1-A)}{\sigma \cdot 4 \cdot\left(\frac{\pi / 2-\psi}{\pi / 2}+\frac{\psi}{\pi / 2} \cdot \frac{1}{1+\cos \psi}\right)}\right]^{1 / 4} \cdot\left(\frac{p_{t}}{p_{0}}\right)^{\alpha}
$$

where $\sigma\left(=5.67 \times 10^{-5} \mathrm{erg} / \mathrm{cm}^{2} \cdot \mathrm{s} \cdot \mathrm{deg}^{4}\right)$ is the Stefan-Boltzmann constant; $b$ is the scaling factor determined by the planet's given surface temperature $T_{S}$ in degrees Kelvin (for Earth $T_{S}=288.2 \mathrm{~K}$ ), the solar constant $S$ (average value for Earth $S=1.367 \times 10^{6} \mathrm{erg} / \mathrm{cm}^{2} \cdot \mathrm{s}$ ), the precession angle $\psi$ (for Earth $\psi=23.44^{\circ}$ ), the planet's albedo $A$ (for Earth $A \approx 0.3$ ) at $p_{t}=p_{0}\left(p_{0}=1 \mathrm{~atm}\right)$, and the adiabatic exponent $\alpha=0.1905$. In this case, $b^{\alpha}=1.093$. At the Earth precession angle $\psi=23.44$, the denominator in Equation (2) is equal to 3.502 (rather than 4 in the classic Boltzmann Equation).

Besides the Equations (1') for $\alpha$, there is another way to determine the same parameter. If gas heat capacity is expressed in $\mathrm{cal} / \mathrm{g} \cdot \mathrm{deg}$, and the gas constant is $R=1.987 \mathrm{cal} / \mathrm{mole} \cdot \mathrm{deg}$, then the adiabatic exponent $\alpha$, as a function of the atmosphere composition and humidity, may be found from the known equations:

$$
\begin{gathered}
\alpha=\frac{R}{\mu \cdot\left(c_{p}+C_{w}+C_{r}\right)} \\
c_{p}=\frac{p_{\mathrm{N}_{2}} \cdot c_{p}\left(\mathrm{~N}_{2}\right)+p_{\mathrm{O}_{2}} \cdot c_{p}\left(\mathrm{O}_{2}\right)+p_{\mathrm{CO}_{2}} \cdot c_{p}\left(\mathrm{CO}_{2}\right)+p_{\mathrm{Ar}} \cdot c_{p}(\mathrm{Ar})}{p}
\end{gathered}
$$

where $\mu \approx 29$ is the air molar weight; $p_{\mathrm{N}_{2}} ; p_{\mathrm{O}_{2}} ; p_{\mathrm{CO}_{2}} ; p_{\mathrm{Ar}}$ are nitrogen, oxygen, carbon dioxide and argon partial pressures; $p$ is total atmospheric pressure; $c_{p}\left(\mathrm{~N}_{2}\right)=0.248 ; c_{p}\left(\mathrm{O}_{2}\right)=0.218 ; c_{p}\left(\mathrm{CO}_{2}\right)=0.197 ; c_{p}(\mathrm{Ar})=0.124$ $\mathrm{cal} / \mathrm{g} \cdot \mathrm{deg}$ are nitrogen, oxygen, carbon dioxide and argon specific heats at constant pressure [12]; $C_{q}=C_{w}+C_{r}$ is the correction factor with the dimension of specific heat (it takes into account the total heating effect of the water vapor condensation processes $C_{w}$ in a humid atmosphere) and the absorption $C_{r}$ of Sun and Earth heat radiation. For planets with different atmospheres, the $C_{q}$ parameter is the characteristic of any physical or chemical process resulting in the heat release (or absorption if $C_{q}<0$ ) within the troposphere. For Earth's atmosphere, the best fit of the adiabatic theory with the standard troposphere model occurs at $\alpha=0.1905$.

The atmosphere specific heat may be estimated from its characteristic temperatures. Let us assume that $Q_{a}$ is the atmosphere's heat content and $m_{a}$ is its mass. Then the atmospheric specific heat radiation component $C_{r}$ may be found from the effective temperature $T_{e}$ as follows:

$$
C_{r}=\frac{Q_{a}}{m_{a} \cdot T_{e}}
$$

Similarly, we may assume that the additional heating of the atmosphere from the planet's effective temperature to its average surface temperature $T_{s}$ is described by the total specific heat:

$$
c_{p}+C_{w}=\frac{Q_{a}}{m_{a} \cdot\left(T_{s}-T_{e}\right)} .
$$

Excluding $Q_{a}$ from the Equations (4) and (4'), 


$$
C_{r}=\left(c_{p}+C_{w}\right) \cdot \frac{T_{s}-T_{e}}{T_{s}}
$$

and, taking Equation (3) into account, one obtains:

$$
\begin{gathered}
C_{r}=\frac{R}{\mu \cdot \alpha} \cdot \frac{T_{s}-T_{e}}{T_{s}} \\
C_{w}=\frac{R}{\mu \cdot \alpha} \cdot \frac{T_{e}}{T_{s}}-C_{p}
\end{gathered}
$$

On substituting the above Earth atmospheric parameter values $\alpha=0.1905, \mu=29, c_{p}=0.2394 \mathrm{cal} / \mathrm{g} \cdot \mathrm{K}, T_{s}=$ $288 \mathrm{~K}$ and $T_{e}=263.5 \mathrm{~K}$ into Equations (5') and (6), one obtains: $C_{r}=0.0306 \mathrm{cal} / \mathrm{g} \cdot \mathrm{K}, C_{w}=0.0897$ and $C_{r}+C_{w}$ $=0.1203$. For the Venus atmosphere with $\alpha=0.1726, \mu=43.2, c_{p}=0.199 \mathrm{cal} / \mathrm{g} \cdot \mathrm{K}, T_{s}=735.3 \mathrm{~K}$ and $T_{e}=228 \mathrm{~K}$, the parameters evaluation result in $C_{r}=0.162, C_{w}=-0.1164 \mathrm{cal} / \mathrm{g} \cdot \mathrm{K}$ and $C_{q}=C_{r}+C_{w}=0.0456$.

To check the accuracy of Equation (2) (used for the determination of temperature distribution in Earth's and Venus's troposphere based on given composition and pressure) the results were compared with the standard temperature distribution in the Earth's troposphere [13] and of Venus troposphere [14]. The present-day surface atmospheric pressures are respectively $p_{s}=1$ and $90.9 \mathrm{~atm}$ with $p_{0}=1 \mathrm{~atm}$; the precession angles are $\psi_{E}=23.44^{\circ}$ and $\Psi_{\mathrm{V}} \approx 3.18^{\circ}$. The results of comparison are presented in Figure 2, which demonstrate perfect fit of the adiabatic model to experimental data.

The quoted comparisons indicate that average temperature distribution in the planet's troposphere is completely defined by the solar constant, atmospheric pressure (mass), heat capacity of its gas composition and the precession angle. The theoretical temperature on Venus surface turned out to be $T_{s}=735 \mathrm{~K}$, and on Earth's surface, $288 \mathrm{~K}$. The empiric values are 735.3 and $288.2 \mathrm{~K}$, respectively. This close fit cannot be accidental and presents the convincing evidence in favor of the adiabatic theory of heat transfer in a dense atmosphere.

Coming back to the temperature distribution on Earth, the heat release from its surface through convection, radiation and the water vapor condensation in the atmosphere is defined by the total heat content associated with the processes. The dry air specific heat is $c_{p}=0.2394 \mathrm{cal} / \mathrm{g} \cdot \mathrm{deg}$, the specific heat of the water vapor is $C_{w}=$ $0.0897 \mathrm{cal} / \mathrm{g} \cdot \mathrm{deg}$, the specific heat associated with radiation is $C_{r}=0.0306 \mathrm{cal} / \mathrm{g} \cdot \mathrm{deg}$, and the Earth's near-surface temperature is $T_{s}=288.2 \mathrm{~K}$.

Using these data, one can determine the three components of the heat flow in the Earth atmosphere $E_{p}, E_{w}$, and $E_{r}$ : for absolutely dry and transparent atmosphere in which heat transfer may occur only through convection $E_{p}=68.99 \mathrm{cal} / \mathrm{cm}^{2}$, for the water vapor condensation process $E_{w}=25.85 \mathrm{cal} / \mathrm{cm}^{2}$, and for the radiation compo-

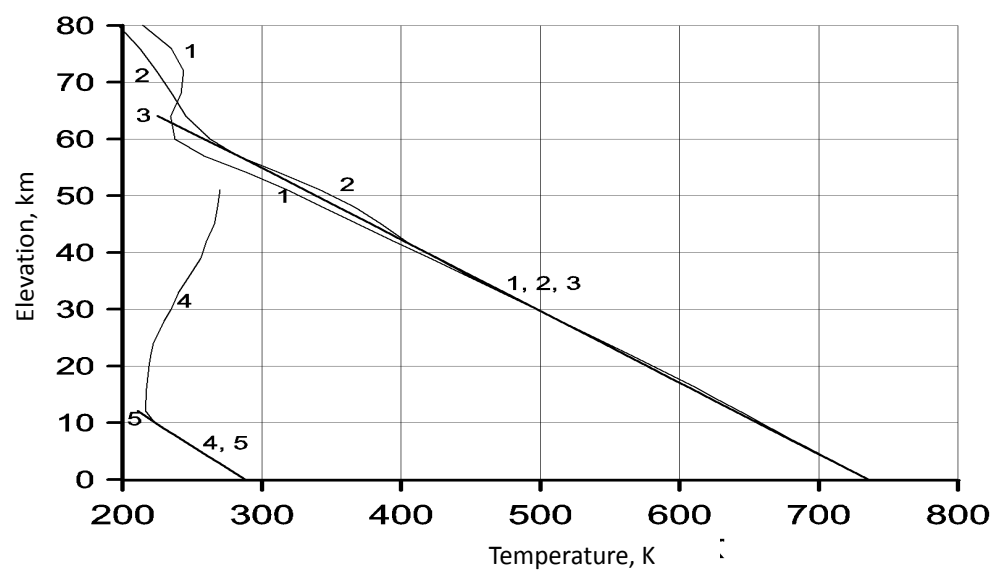

Figure 2. Experimental temperature distribution in Earth's troposphere and stratosphere (curve 4) and in Venus's troposphere (1 and 2) (Planet Venus, 1989) compared with averaged theoretical distributions (5 and 3) based on physical (adiabatic) theory of the greenhouse effect (the temperatures are in absolute degrees Kelvin). 
nent $E_{r}=8.82 \mathrm{cal} / \mathrm{cm}^{2}$. Thus, the contribution to the heat transfer from convection component is about $66.55 \%$, from the water vapor condensation processes $24.94 \%$, and from radiation (by "greenhouse gases") only $8.51 \%$ (see Figure 3).

\section{Impact of the Increased Content of $\mathrm{CO}_{2}$ on Global Climate Changes}

It is important to note that increase in the heat absorption in the troposphere by $\mathrm{CO}_{2}$ and other "greenhouse gases" results only in a decrease of the adiabatic exponent $\alpha$. Besides, the carbon dioxide atmosphere has greater density than the nitrogen-oxygen atmosphere and methane has lower density so that the same pressures in these atmospheres will be reached at different elevations $h$ than those in the nitrogen-oxygen atmosphere:

$$
h_{\mathrm{CO}_{2}}=h_{\mathrm{N}_{2}+\mathrm{O}_{2}} \cdot \frac{\mu_{\mathrm{N}_{2}+\mathrm{O}_{2}}}{\mu_{\mathrm{CO}_{2}}}
$$

and

$$
h_{\mathrm{CH}_{4}}=h_{\mathrm{N}_{2}+\mathrm{O}_{2}} \cdot \frac{\mu_{\mathrm{N}_{2}+\mathrm{O}_{2}}}{\mu_{\mathrm{CH}_{4}}}
$$

where

$\mu_{\mathrm{N}_{2}+\mathrm{O}_{2}}=28.9$ is the molar weight of the nitrogen-oxygen atmosphere,

$\mu_{\mathrm{CO}_{2}}=44$ is the molar weight of the carbon dioxide atmosphere, and

$\mu_{\mathrm{CH}_{4}}=16$ is the molar weight of the methane atmosphere.

Thus, one comes to a seemingly paradoxical conclusion that absorption of the IR radiation in the troposphere does not increase but, conversely, only lowers the temperature of the planet's troposphere (see Figure 4).

The near surface temperature of the hypothetical methane atmosphere will be $288.1 \mathrm{~K}$ which is just $0.1^{\circ} \mathrm{C}$ above the usual average Earth's temperature of $288 \mathrm{~K}$. The temperature distributions within the hypothetical totally carbon dioxide and totally methane atmospheres were presented by Chilingar et al. [15] together with the temperature distribution in the existing nitrogen-oxygen atmosphere. For a hypothetical methane atmosphere, the near surface temperature at sea level remains almost unchanged, because the corresponding values of the coefficient $\alpha$ are almost the same ( 0.1905 for the nitrogen-oxygen atmosphere and 0.1915 for the totally methane atmosphere).

Physically, an explanation of the cooling effect of the atmosphere with the high content of "greenhouse gases" is the high efficiency of the convective heat transfer from the planet's surface to the lower stratosphere, from which this heat is rapidly dissipating into the outer space through radiation. As the greenhouse gases absorb the

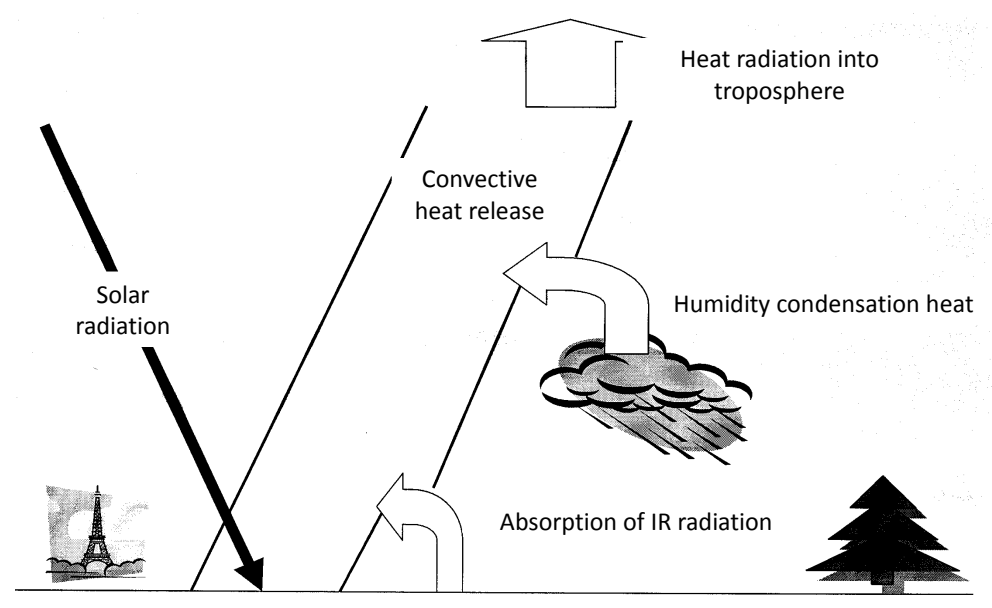

Figure 3. Heat transfer balance in Earth troposphere: $66.6 \%$ of the heat is lost through the air convection, $24.9 \%$, with humidity condensation, and only $8.5 \%$, with radiation. 
Earth's heat radiation in the lower layers of troposphere, its energy transforms into the heat oscillations of the gas molecules. This, in turn, leads to expansion of the gas mixture and its rapid ascent to the stratosphere where the heat excess is lost through radiation into the outer space.

To replace these volumes of the warm air, the already cooled air descends from the upper troposphere. As a result, the global average atmospheric temperature slightly decreases. One particular consequence of it is that with an increase in the carbon dioxide and methane contents in troposphere the convective mass exchange of the atmospheric gases must substantially accelerate. Thus, it is not out of the question that the intensification of synoptic processes in Earth troposphere (but not temperature increase) may be a result of the carbon dioxide and other "greenhouse gases" accumulation.

Similarly, if one mentally replaces Venus's carbon dioxide atmosphere by the nitrogen-oxygen atmosphere at the same pressure of $90.9 \mathrm{~atm}$, its surface temperature would increase from $735.3 \mathrm{~K}$ to $793.4 \mathrm{~K}$ (or from 462 to $520^{\circ} \mathrm{C}$, see Figure 5).

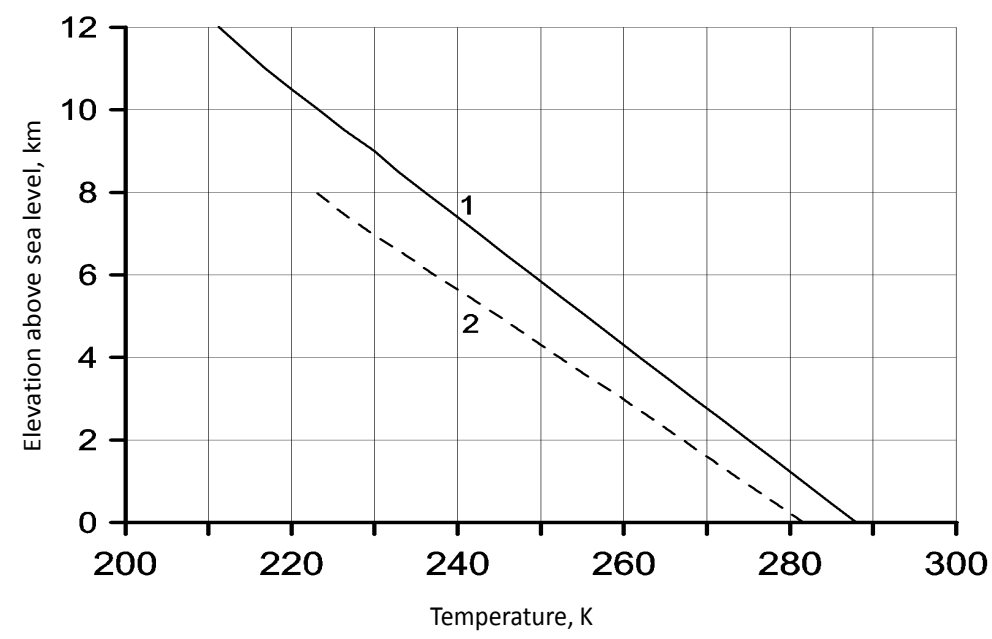

Figure 4. Averaged temperature distributions in Earth's troposphere [6]: 1. For actual model of Earth's atmosphere with the nitrogen-oxygen air mix; 2. For Earth's atmosphere model with the carbon dioxide air composition (all other parameters are the same as in the standard model 1). Comparison of the graphs shows that $\mathrm{CO}_{2}$ accumulation results in climate cooling.

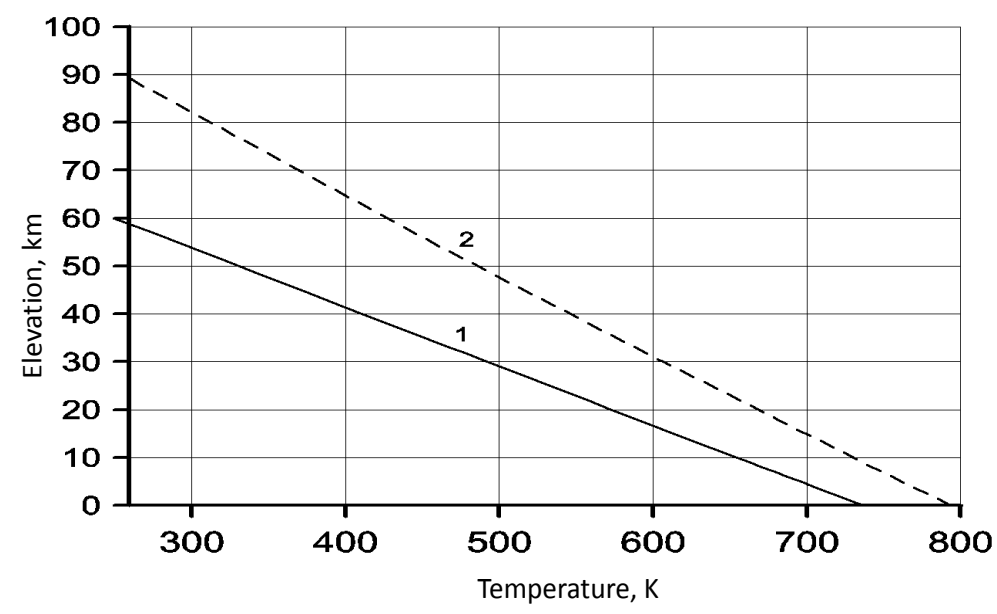

Figure 5. Averaged temperature distributions in Venus's troposphere based on Equation (2) (After Sorokhtin, Chilingar, and Khilyuk, 2007) [6]: 1. Temperature distribution for the real carbon-dioxide Venus troposphere (above 60 $\mathrm{km}$ ); 2. Temperature distribution for a hypothetical model of nitrogen-oxygen Venus troposphere, all other conditions being constant. 


\section{Impact of Increased Content of $\mathrm{CH}_{4}$ on Global Climate Changes}

Methane molecules have a high capacity of absorption of the infrared photons. According to estimates of EPA, the GWP (Global Warming Potential) of methane is 21 times higher than GWP of carbon dioxide over the 100 year time span. Light methane released in the atmosphere ascends into its upper layers where it initially reacts with ozone, ultimately producing (through the chain of reactions) water and carbon dioxide.

This process of chemical reactions can be summarized in a single equation as follows:

$$
\text { (3) } \mathrm{CH}_{4}+(4) \mathrm{O}_{3}=(3) \mathrm{CO}_{2}+(6) \mathrm{H}_{2} \mathrm{O}
$$

The "greenhouse gases" involved in the reaction absorb infrared radiation at different parts of the infrared spectrum. The rate of oxidation primarily depends on availability of the free $\mathrm{OH}$ radicals. The estimated by IPCC and adapted by EPA [16], the methane life-time in the atmosphere is in the range of 8 - 12 years.

Based on these considerations one can consider the global warming (cooling) effect of the methane releases as the effect of supplying additional amount of $\mathrm{CO}_{2}$ corresponding to the amount (and corresponding absorption capacity) of $\mathrm{CO}_{2}$. (For every molecule of $\mathrm{CH}_{4}$ one can substitute 21 molecules of $\mathrm{CO}_{2}$ ). Thus, one can analyze the radiation warming (cooling) effect of methane as the effect of additional concentration 21 times 1.8 ppm of $\mathrm{CO}_{2}$. This additional concentration of $\mathrm{CO}_{2}(37.8 \mathrm{ppm})$ leads to cooling of the atmosphere as a result of increased convection in the lower layers of the troposphere. Oxidation of methane is a main source of water vapor in the upper stratosphere. The methane gas together with the water vapor shields the Earth's surface from the solar irradiation, thus lowering the average Earth surface temperature.

Therefore, it turns out that the common concept of Earth's climate warming due to accumulation of the anthropogenic $\mathrm{CO}_{2}$ and other "greenhouse gases" is a myth. On the contrary, the atmospheric accumulation of $\mathrm{CO}_{2}$ and $\mathrm{CH}_{4}$, with all other conditions constant, can result only in the global climate cooling and in somewhat increased synoptic activity in the Earth's troposphere. There is currently not a single proven fact of the "greenhouse gases” effect on Earth's climate.

A detailed correlation of the Arctic near-surface temperatures with the pulsations of solar radiation is provided in Figure 6 [17]. Using these data and the graphs of the anthropogenic $\mathrm{CO}_{2}$ accumulation, Robinson et al. [18] showed without any doubt that the carbon dioxide concentration in Earth's atmosphere has no effect on Earth climate. Moreover, in view of 60-year fluctuations of the solar activity and the fact that the last cycle of the fluctuation began around 1970, it may be expected that the next cool down will occur within 20 to 30 years.

In summary, the authors would like to draw attention of the scientists and politicians to the fact that numerous traditional and "classical" model forecasts of the climate changes caused by the atmospheric releases of the socalled "greenhouse" gases are as a rule based on intuitive considerations. Besides, there is currently not a single proven fact of the "greenhouse gases” effect on Earth's climate.

\section{Conclusion}

The writers investigated the greenhouse effect using their adiabatic model, which relates the global temperature of troposphere to the atmospheric pressure and solar radiation. This model allows one to analyze the global-

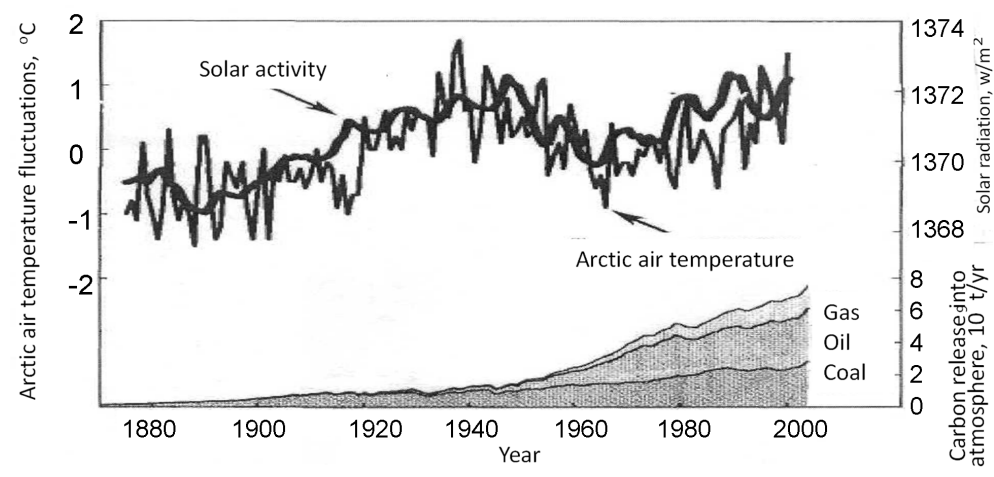

Figure 6. Near-surface temperature in the Arctic vs. solar activity (after Robinson et al., 2007) [17]. 
temperature changes due to variations in mass and chemical composition of the atmosphere. Even significant releases of anthropogenic carbon dioxide and methane into the atmosphere do not change average parameters of the Earth's heat regime and have no essential effect on the Earth's climate warming. Moreover, based on the adiabatic model of heat transfer, the writers showed that additional releases of $\mathrm{CO}_{2}$ and $\mathrm{CH}_{4}$ lead to cooling (and not to warming as the proponents of the conventional theory of global warming state) of the Earth's atmosphere. The additional methane releases possess a double cooling effect: First, they intensify convection in the lower layers of troposphere; Second, the methane together with associated water vapor intercept part of the infrared solar irradiation reaching the Earth. Thus, petroleum production and other anthropogenic activities resulting in accumulation of additional amounts of methane and carbon dioxide in the atmosphere have practically no effect on the Earth's climate.

\section{References}

[1] Sorokhtin, O.G., Chilingar, G.V., Khilyuk, L.F. and Gorfunkel, M.V. (2007) Evolution of the Earth’s Global Climate. Energy Sources, Part A, 29, 1-19.

[2] Arrhenius, S. (1896) On the Influence of Carbonic Acid in the Air upon the Temperature of the Ground. Philosophical Magazine, 41, 237-276. http://dx.doi.org/10.1080/14786449608620846

[3] Budyko, M.H. (1997) The Carbon Dioxide Problem. Gidrometeoizdat, Sankt Petersburg, 60 p.

[4] Gore, A. (2006) Inconvenient Truth. Rodale Books, 328 p.

[5] Sorokhtin, O.G. (1990) Greenhouse Effect of Atmosphere in the Geological History of EARTH. Doklady Akademii Nauk SSSR, 315, 587-592.

[6] Sorokhtin, O.G., Chilingar, G.V. and Khilyuk, L.F. (2007) Global Warming and Global Cooling: Evolution of Climate on Earth. Elsevier, Amsterdam, 313 p.

[7] Kotlyakov, V.M. (2000) Glaciology of Antarctica. Nauka, Moscow, 384 p.

[8] Fischer, H., Wahlen, M., Smith, J., Mastroianni, D. and Deck, B. (1999) Ice Core Records of Atmospheric $\mathrm{CO}_{2}$ around the Last Three Glacial Terminations. Science, 283, 1712-1714. http://dx.doi.org/10.1126/science.283.5408.1712

[9] Landscheidt, T. (2003) New Little Ice Age Instead of Global Warming? Energy and Environment, 14, 327-350. http://dx.doi.org/10.1260/095830503765184646

[10] Sorokhtin, O.G., Chilingar, G.V., Sorokhtin, N.O. and Gorfunkel, M.V. (2011) Evolution of Earth and Its Climate: Birth, Life and Death of Earth. Elsevier, Amsterdam, 763 p.

[11] Landau, L.D. and Lifshits, E.M. (1979) Statistical Physics, Part 1. Nauka, Moscow, 559 p.

[12] Naumov, G.B., Ryzchenko, B.N. and Khodakovskiy, I.L. (1971) Reference Book of Thermodynamic Characteristics. Atomizdat, Moscow, 240 p.

[13] Bachinskiy, A.I., Putilov, V.V. and Suvorov, N.P. (1951) Handbook of Physics. Uchpedgiz, Moscow, 380 p.

[14] (1989) Venus (Atmosphere, Surface and Structure). Nedra, Moscow, 482 p.

[15] Chilingar, G.V., Sorokhtin, O.G., Khilyuk, L. and Gorfunkel, M.V. (2009) Greenhouse Gases and Greenhouse Effect. Environmental Geology, 58, 1207-1213. http://dx.doi.org/10.1007/s00254-008-1615-3

[16] EPA (2010) Methane and Nitrous Oxide Emissions from Natural Sources. US Environmental Protection Agency, Washington DC.

[17] Robinson, A.B., Robinson, N.E. and Soon, W. (2007) Environmental Effects of Increased Atmospheric Carbon Dioxide. Journal of the American Physicians and Surgeons, 12, 79-90.

[18] Robinson, A.B., Baliunas, S.L., Soon, W. and Robinson, Z.W. (1998) Environmental Effects of Increased Atmospheric Carbon Dioxide. Journal of the American Physicians and Surgeons, 3, 171-178. 
Scientific Research Publishing (SCIRP) is one of the largest Open Access journal publishers. It is currently publishing more than 200 open access, online, peer-reviewed journals covering a wide range of academic disciplines. SCIRP serves the worldwide academic communities and contributes to the progress and application of science with its publication.

Other selected journals from SCIRP are listed as below. Submit your manuscript to us via either submit@scirp.org or Online Submission Portal.
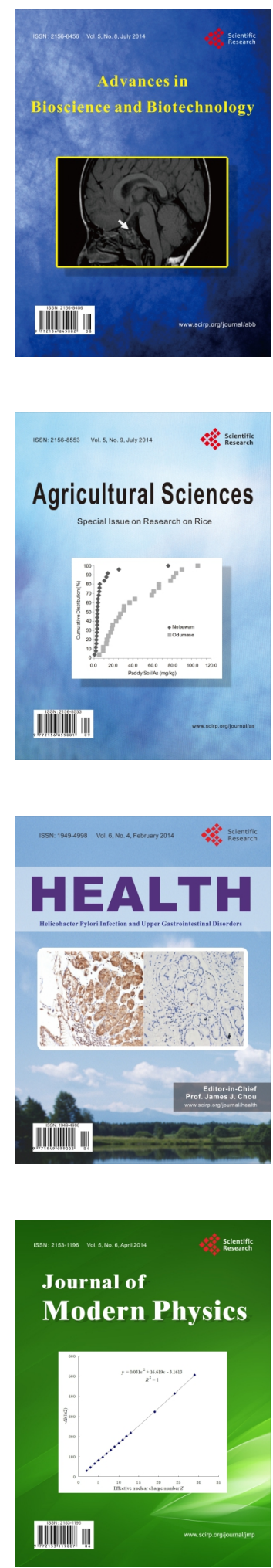
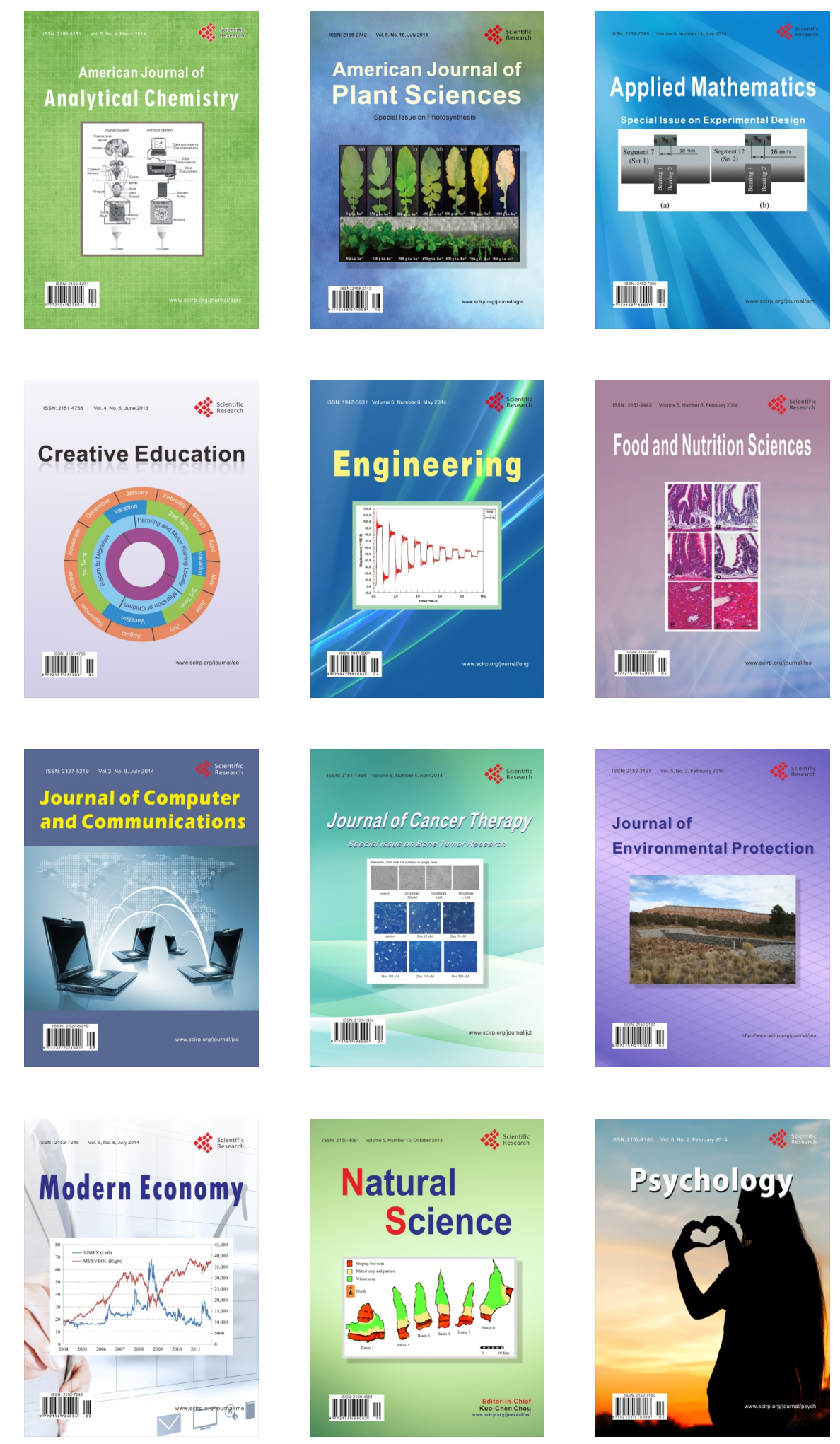